\title{
Deployment of product configurators: analysis of impacts within and outside the user company
}

\author{
Gianluca D'Antonio ${ }^{1}$, Sara Mottola ${ }^{2}$, Giovanni Prencipe ${ }^{2}$, \\ Arianna Rosa Brusin ${ }^{2}$, Joel Sauza Bedolla ${ }^{1}$, Paolo Chiabert ${ }^{1}$ \\ ${ }^{1}$ Politecnico di Torino, corso Duca degli Abruzzi 24, 10129, Torino, Italy \\ ${ }^{2}$ Alta Scuola Politecnica, corso Duca degli Abruzzi 24, 10129, Torino, Italy \\ \{gianluca.dantonio,joel.sauza, paolo.chiabert\}@polito.it \\ \{sara.mottola, giovanni.prencipe, arianna.rosa\}@asp-poli.it
}

\begin{abstract}
Today many companies throughout the world recognize the need to provide outstanding service to customers: for both mass market products and products devoted to professionals, an increasing level of customization is required. This, in turn, leads to high variability in design and manufacturing processes. Hence, a structured approach to manage such variability is necessary. For an effective mass-customization program, two organizational design principles could be introduced: (i) the definition of a set of standard modules and functional criteria; (ii) the development of a tool enabling customers designing his own product. The present paper aims to analyze the impacts of a product configurator, both inside and outside of a manufacturing company. Within the internal analysis, the studied aspects include business model transformation, organization change, economic benefits. The external impacts mainly involve supply chain effects, consequences on brand perception, and impacts on society. The presented analysis is applied to a manufacturer of machines for mixing inks.
\end{abstract}

Keywords: mass customization, modularization, product configurator, SCM-NPD alignment, impacts.

\section{Introduction}

In the last years, customers demand has been characterized by increasingly specific and complex requirements, leading to a broadened product variety. The direct effect of this phenomenon is the necessity, for companies, to produce high volumes of customized goods. However, beside customers satisfaction, companies must also keep manufacturing profitability and remain competitive. Therefore, the increase of product variety must cope with strategies for cycle time reduction, adaptation to changing (or new) markets and transformation of product development processes [1]. 
A strategy to overcome some of the above-mentioned issues is Mass Customization (MC): it is the ability to supply customized products or services through flexibility in processes, integration and agility [2] in the supply chain.

In literature, strategies for managing $\mathrm{MC}$ have already been developed. For example, Mikkola and Skjøett-Larsen [3] showed how MC can be achieved through the integration of the customer in the supply process, with co-design and, in some cases, co-production. Another way to deal with MC is the implementation of a product configurator, a software-based expert system that supports the user in the creation of product specifications by restricting the way to combine predefined entities and their properties [4]. Unfortunately, often Small and Medium Enterprises (SMEs) cannot afford the adoption of such tool; a methodology devoted to this kind of companies to tackle this issue is presented in [5]. However, the adoption of a product configurator may lead to significant changes in the organization of a company, with an impact relatively higher than in big companies. Hence, the present paper aims to present a comprehensive methodology for the overall analysis and evaluation of the changes related to the introduction of a product configurator. ,Furthermore, the implication of this tool as an important step for the shift from an Engineering-to-order (ETO) to an Assembly-to-order (ATO) strategy will be analysed in detail.

The remainder of the paper is organized as follows: in Section 2 the state of the art is reviewed. The methodology for evaluating the impact of product configurator is described in Section 3. The case-study to validate the methodology is presented in Section 4: it is based on a manufacturer of machines for mixing inks. Conclusive remarks and hints for future works are provided in Section 5.

\section{Literature review}

The development in Information Technology (IT) made available also for SMEs a class of software tools called 'product configurator': they are "a software-based expert system that supports the user in the creation of product specifications" through the combination of different standard modules [4], and enable to reduce the trade-off between product variety and delivery time [6]. A standard module is a consistent product unit that can be identified and replaced in the product architecture several times to boost product variety and adaptability [7]. A product configurator is an important tool for the alignment of the supply chain to a new product development, assuring the coordination between the development of new products and the business processes [8]. Moreover, configuration design has been recognized as an effective means to implement mass customization [9].

Empirical studies were performed in order to identify all the consequences that a product configurator generates for a company and its surrounding environment. The findings from the literature can be classified in the following two classes.

Impacts on the internal business activities. Zhang et al. [10] developed an analysis on the implications of product configurators on companies' business activities. Changes result in sales order processing, generation of BOMs and 
manufacturing documentation. Such changes can be supported by the integration between the product configurator and the Enterprise Resource Planning (ERP) of the company [8]. The automation of traditionally manual activities leads to a substantial reduction in the time necessary for processing orders and for design [8] [10] and, in turn, to an overall lead time reduction which is particularly significant for engineering oriented companies [4]. In highly-complex products, the adoption of a product configurator also drives to improved quality, preservation of knowledge, lowered time for employees training and improved certainty of delivery [4]. The latter point is achieved from the standardization of the selling process, which reduces the possibility of changes by the customer in the product design after the order has been approved.

Other impacts on the internal business activities, in terms of performance improvements, are identified by Zhang [10]: increased correct sales order, increased customers' orders and increased IT capacity. Beside the business tasks, possible changes concerning the company internal organization must be taken into account. The automation of design activities may lead employees to reject the novel tool, considering it as a threat for their position [10].

Impacts on the supply chain. The effective adoption of a product configurator requires tight collaboration and integration with the two terminal nodes of the supply chain system, namely customers and suppliers. A product configurator promotes co-design processes in which the customers are actively involved in the design of their product, and, in some cases, in the production [3]. Hence, considering both sides of the supply chain, suppliers and customers become key partners. To this purpose, Belkaldi [7] underlines the importance of linking a modular product strategy with the suppliers' selection, particularly for original equipment manufacturers (OEM).

\section{Methodology}

In order to evaluate the effects due to the adoption of a product configurator on both the company and its supply chain, a four steps methodology has been developed. It is partially based on the frameworks proposed in [11] and [12]. In the twodimensional matrix, shown in Fig. 1, different managerial approaches are proposed based on the level of complexity and customization of products. In the second framework, different variables have been considered for the purpose of supply chain alignment, from a point a view of NPD and supply chain design, planning and management. The original contribution of this work is the adaptation of these models to small ETO companies, which is currently missing in literature.

\subsection{Analysis of the as-is business model}

A preliminary analysis is necessary to point out the initial background. In particular, a deep awareness about the company business model, the stakeholders, their role 


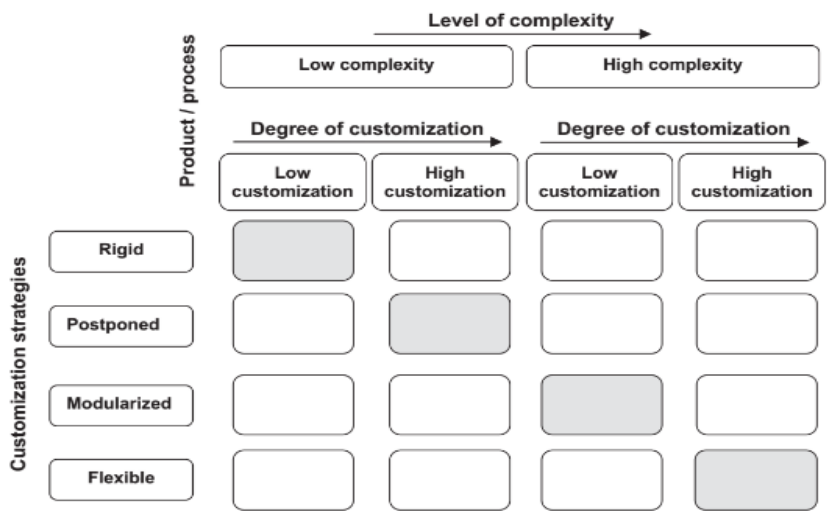

Fig. 1 Interpretative framework for mass customization. Picture taken from [11].

and interaction with the supply chain is necessary. The business model canvas [13] is an effective tool to support this task.

In particular, the value proposition of the products to be managed through the configurator must be analyzed. The target customers for such products are identified, as well as the valuable features they are willing to pay for. This step is crucial, since the configurator adoption also impacts on the relationship and the communication between the company and its customers. Key activities and resources are analyzed to identify the outsourced activities, the suppliers and their role. The key partners represent the upstream side of the supply chain and could be integrated into the manufacturing process, on the basis of the specific strategy implemented. Finally, revenues streams and costs are strictly linked to the other elements of the business model: they support, in the following steps, the analysis of the economic impacts.

\subsection{Analysis of the internal organization}

In this phase, the causality relationships tied to configurator adoption are analysed: on the one side, the reasons leading to this decision must be stated; on the other side, the expectations on future performances must be evaluated, as well as the actions and the technical decisions necessary to develop and implement the solution. Finally, the activities required to integrate the configurator into the supply chain and bring it to a fully working regime must be described.

The effective adoption of a product configurator requires that an appropriate manufacturing strategy is set and implemented. In particular, product and process standardization, decoupling point positioning and material flow setting represent the main strategic levers. To this purpose, a framework for decision support has been proposed by Brun and Zorzini [11]; it considers two factors - product complexity and customization level - to identify the most suitable manufacturing strategy. The two above-mentioned factors could be interpreted as "Internal/technological product variety" and "External/required product variety". 


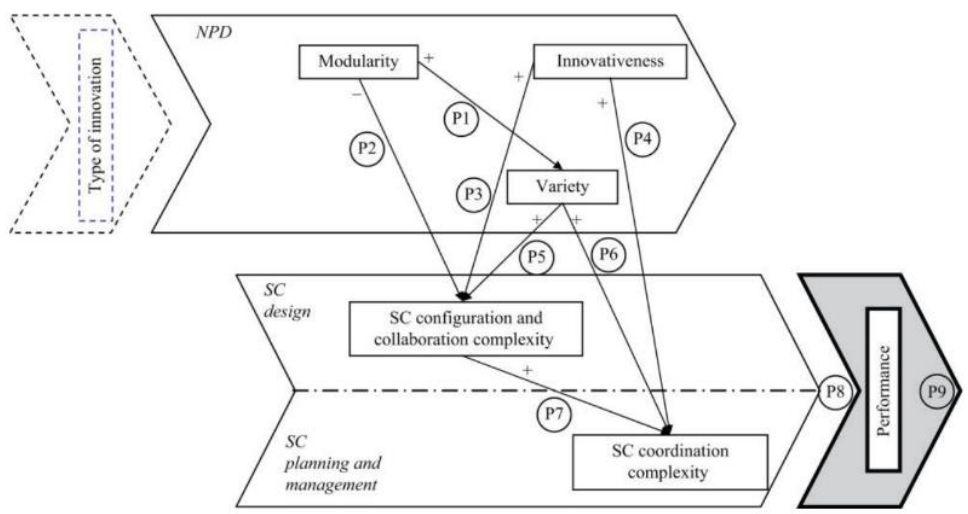

Fig. 2 Framework for supply chain alignment. Picture taken from [12].

Since the volume is linked to the product variety, through a strong trade-off - the higher the variety granted to lower the volume realizable [14] - this model seems to be particularly comprehensive. This framework has been validated for medium and big companies; however, since SMEs are often required to directly face the trade-off among the variety, volume and customization (e.g. mass customization), hybrid strategies can also be considered.

Finally, some considerations are done with respect to the product life cycle length and the innovation rate within the market. In fact, the introduction of a product configurator cannot make the system rigid at all with respect to the product innovation over time, but should support it.

\subsection{Analysis of the supply chain}

Beside the manufacturing strategy redefinition, the alignment between the product development and the supply chain must also be considered: the modularization of the finite product also involves the suppliers.

Here, the framework developed in [12] is adopted to analyze the impacts of modularization on the products variety and on the supply chain integration and collaboration. The application of this framework requires the introduction of the product configurator to be considered as an independent variable. Then the effects of this novel element on the supply chain are analysed, as well as the link between product modularity and innovation. A schematic representation of the framework is shown in Fig. 2.

\subsection{Definition of the to-be state}

The last step of the methodology is represented by the definition of the target condition: a description of the company and the supply chain, after having introduced the product configurator and set the manufacturing strategy, is made. 
All these factors are synthesized within a comprehensive framework, which has to join the business model canvas and the supply chain representation. An overview of the methodology is shown in Fig. 3.

\section{Case study}

In this section the methodology presented in the previous section is applied to a real case study. The introduction of a product configurator within an Italian SME that assemblies dispensing systems for inks and paintings is considered. The analysis presented in this work involves the most customizable family of products.

The introduction of a product configurator is strongly supported by the company; in particular, the design lead time is expected to be dramatically shortened and the accuracy of the design is supposed to be increased, due to a more inclusive approach in customers involvement. However, most of the existing product configurators are designed for business-to-customer companies; here, the challenge is to shift the approach to a business-to-business company.

\subsection{Analysis of the as-is business model}

The business model canvas has been used to perform the analysis of the current state of the company.

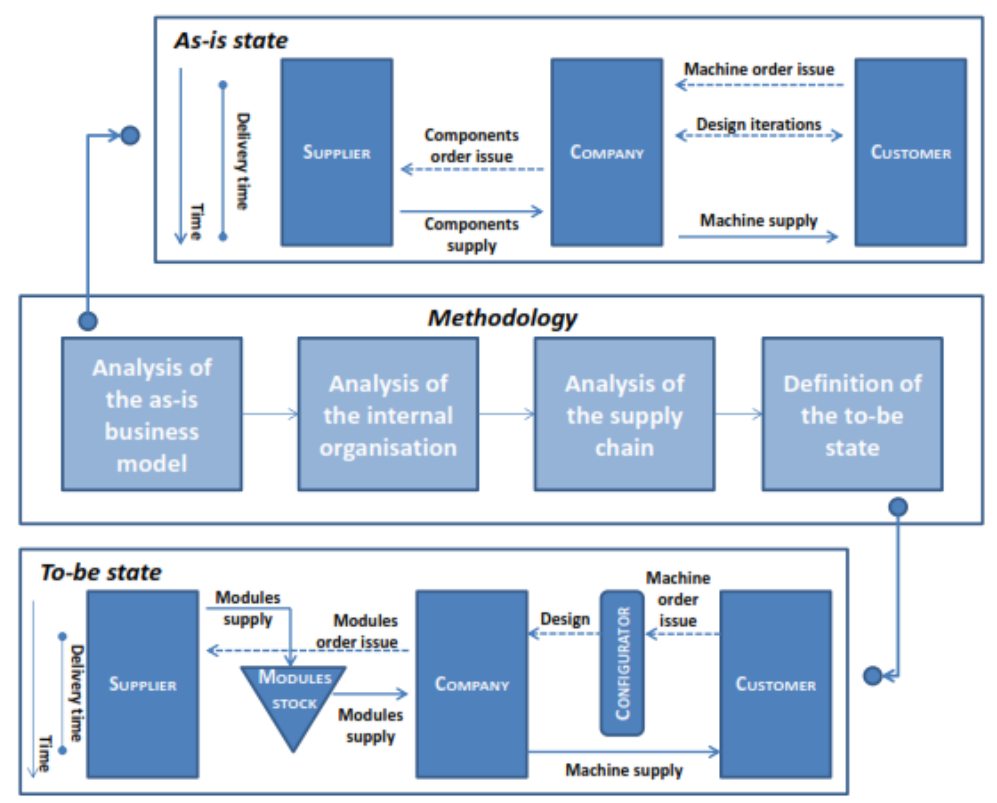

Fig. 3 Framework for the followed methodology. 
- Value proposition. Dispensing systems for mixing inks and paintings are sold; the portfolio is composed by highly customizable products.

- Customers. Producers and retailers of inks and paintings; they are spread all over the world.

- Relationship and communication with customers. Dealers interact with the customers and collect the orders for new machines. Then, the order is transmitted to the engineering department.

- Key activities.Marketing, design, and upstream logistics.

- Key resources.Company engineers and designers.

- Key partners.Suppliers of materials (raw material, components, semi-finished products) and suppliers of workforce.

- Revenues. Machines sales.

- Costs. The main sources of cost are engineering, logistics, and outsourced manufacturing activities.

\subsection{Analysis of the internal organization}

Before the introduction of the product configurator, the customer order contained a set of requirements and a company employee was in charge of designing and validating the structure of the machine. However, the company found that the products exhibit an excessive variability, affecting both design and manufacturing resources. Therefore, an action to reduce the design effort is necessary to focus the existing resources in more added value, challenging projects.

A postponed manufacturing approach was used, since all the tasks necessary to provide a customer with his product were performed after the order is signed. Further, in agreement with the Wortmann classification, the company could be classified as an ETO manufacturing system.

In the company vision, the adoption of product configurator was accompanied by a standardization effort, with the aims of reducing the effort necessary for designing highly customized machines and maintaining a high level of perceived flexibility. The company portfolio exhibit a low innovation rate; this long life cycle does not require frequent changes in product definition, hence modules do not need frequent updates.

The methodology to develop standard modules is presented in [5]. This approach leads to a potential increase of product variety: several variants can be obtained by combining the modules in different ways, on the basis of customers' requirements. Therefore, the complexity of the product is increased, although standardization can ease product management.

Hence, after the implementation of the product configurator a hybrid approach mixing postponement and modularization is to be pursued. The most common and required parts of the machines can be modularized and assembled during idle times. Conversely, the realization of non-standard parts is dealt in a postponed approach.

The definition of standard modules can lead to the desired reduction of design times; however, the overall lead time is shortened since an order decoupling point 
is introduced between the modules preparation and the final assembly phase, as shown in the next step.

\subsection{Analysis of the supply chain}

The deployment of the hybrid manufacturing approach, made of postponement and products modularization, also requires tight collaboration and integration with the suppliers. The company at stake requires partners to supply both components and materials, as well as workforce to assembly the finite product.

Suppliers of physical entities may be required to provide entire modules rather than simple components. Since such modules can be assembled before an order is issued, the suppliers can organize their work in an autonomous manner. The company just needs a limited amount of modules and components in the warehouse, to face customization requests or priority orders. On the other side, such modules and the operators for the final assembly must be provided to the company as soon as an order is issued: hence, a security stock level of modules must be kept and the production plans must be aligned with the needs of the company.

\subsection{Definition of the to-be state}

After the introduction of the product configurator, the major changes in the business model involve the relationship and the communication with the customers. The new system enables to involve the customer into the process, through a product codesign; this, in turn, leads to change one of the tasks included in the key activities. Furthermore, important changes must be highlighted in terms of key resources: the configurator could be strong resource for building and keeping a competitive advantage on the market. In fact, the novelty factor of using a product configurator also into a B2B market and, in particular, within this specific industry, could create a differentiation with respect to the other competitors during the first period. As pointed out in the previous section, the relationship with the key partners is also transformed because a higher level of integration and collaboration with the suppliers is necessary. Revenues are expected to increase because of an expected increase of orders [10] moreover a possible premium price could be applied in order to have very fast deliveries. Finally, costs are expected to be decreased: the shortened lead time, the effort reduction in design and the optimized material management lead to higher efficiency. Furthermore, the increased accuracy in the order technical features will result in a reduction of reworking activities.

All these changes lead to shift the initial ETO configuration towards an Assembly-to-Order (ATO) system. This paradigm change is marked by the introduction of an order decoupling point between the production of different modules and the assembly phase of the finite product. As a consequence, the final assembly can start as soon as the order arrives from the product configurator. A strategic inventory level is kept in order to satisfy the average demand. This approach, in turn, leads to a balance between the material availability and the 
inventory costs: modules are always available at stock, but over-stock costs are avoided.

The impacts on the internal organization must be carefully handled. As stated, the product configurator affects design, which is a key activities. The deployment of an automation tool for this task can be misunderstood by the employees; the company must clarify that the configurator is used to replace repetitive, boring tasks and to focus the resources on more challenging projects with a higher added value.

The decreasing of delivery lead time and the increased accuracy are impacts affecting both the company and the entire supply chain. In fact, the reduced lead time allows the company and the suppliers to better organize their manufacturing systems and directly link them to the demand, and to reach significant internal economies; with respect to the customer, the reduction of lead time leads to a differential factor, a competitive advantage, if comparing the company with its competitors.

The increased accuracy avoids the occurrence of reworking costs or the application of penalties for the company; while the customer can surely base itself on a reliable manufacturing system.

\section{Conclusions}

The present paper has provided insights regarding the deployment of a product configurator within an ETO company. The product configurator represents an effective way to deal with mass customization. In order to make it work effectively, it requires deep changes in terms of both production processes and supply chain structure. These changes result into the transformation of the ETO system in an ATO, allowing the repositioning of the order decoupling point.

A four-step methodology has been presented in order to describe all the phases necessary to start-up the configurator and achieve a steady-state condition, and to assess the impact of such tool in a multi-faced way: the business model, the internal structure and the relationships with the suppliers of a company. The methodology is devoted to support SMEs, overcoming the limit of the literature, which is mainly focused on big companies. The methodology has been validated through the case study of a company that assembles machines for mixing inks and paintings. At the moment of writing this paper, the company is validating the configurator and is starting its deployment. The main challenge for system implementation has been the lack of structured knowledge. The size of the company and the ETO approach led to a proliferation of practices and solutions which - in some cases - were not the best ones. Thus, a fundamental step for this approach is to structure company expertise according to standard criteria; to guarantee the success of this task, the cooperation of company executives and employees is mandatory.

\section{Acknowledgments}


This work has been supported by Alta Scuola Politecnica (ASP), an educational Programme funded by Politecnico di Torino and Politecnico di Milano (Italy) devoted to promising students in Engineering and Architecture, based on ad-hoc courses and the development of multidisciplinary projects. http://www.asp-poli.it.

\section{References}

[1] Eigner, M., Fehrenz, A.: Managing the product configuration throughout the lifecycle. In: 8th International Conference on Product Lifecycle Management, Eindhoven, Netherlands, pp. 396-405 (2011).

[2] Davis, S.M.: Future perfect. Addison-Wesley, Boston (1987).

[3] Mikkola, J. H., Skjott-Larsen, T.: Supply-chain integration: Implications for mass customization, modularization and postponement strategies. Production Planning and Control 15(4), 352-361 (2004). doi: 10.1080/0953728042000238845

[4] Haug, A., Hvam, L., Mortensen, N.: Definition and evaluation of product configurator development strategies. Computers in Industry 63(5), 471-481 (2012). doi: 10.1016/j.compind.2012.02.001

[5] Sauza Bedolla, J., Amato, S., Fantetti, A., Radaelli, A., Saja, A., D'Antonio, G., Chiabert, P.: Product configuration: a standardization methodology to support mass customization. In: 14th International Conference on Product Lifecycle Management, Seville, Spain (2017).

[6] Forza, C., Salvador, F.: Product configuration and inter-firm coordination: an innovative solution from a small manufacturing enterprise. In: The Fourth SMESME International Conference Technology Transfer in SMEs, Aalborg, Denmark (2002).

[7] Belkadi, F., Gupta, R., Vlachou, E., Bernard, A., Mourtis, D.: Linking modular product structure to suppliers' selection through PLM approach: A frugal innovation perspective. In: 13th International Conference on Product Lifecycle Management, Columbia, USA (2016).

[8] Hvam, L., Bonev, M., Denkena, B., Schürmeyer, J., Dengler, B.: Optimizing the order processing of customized products using product configuration. Production Engineering 5(6), 595-604 (2011). doi: 10.1007/s11740-011-0334-x.

[9] Zhou, C., Lin, Z., Liu, C.: Customer-driven product configuration optimization for assemble-to-order manufacturing enterprises. International Journal of Advanced Manufacturing Technology 38, 185-194 (2008). doi: 10.1007/s00170-007-1089-6.

[10] Zhang, L.L., Helo, P.T., Kumar, A., You, X.: An empirical study on product configurators' application: Implications, challenges and opportunities. In: The 17th International Configuration Workshop, Vienna, Austria, pp. 5-10 (2015).

[11] Brun, A., Zorzini, M.: Evaluation of product customization strategies through modularization and postponement. International Journal of Production Economics 120(1), pp. 205-220 (2009). doi: 10.1016/j.ijpe.2008.07.020.

[12] Pero, M., Abdelkafi, N., Sianesi, A., Blecker, T.: A framework for the alignment of new product development and supply chains. Supply Chain Management: An International Journal 15(2) 115-128 (2010). doi: 10.1108/13598541011028723.

[13] Osterwalder, A., Pigneur, Y.: Business model generation. A handbook for visionaries, game changers and challengers, John Wiley \& Sons, Hoboken (2010).

[14] Slack, N., Brandon, J., Johnson, R., Betts, A.: Operations and process management. 
Principles and practice for strategic impact, Pearson, London (2012). 